\title{
Peutz-Jeghers syndrome: Skin manifestations and endocrine anomalies (Review)
}

\author{
FLORICA SANDRU ${ }^{1,2}$, AIDA PETCA ${ }^{3,4}$, MIHAI CRISTIAN DUMITRASCU ${ }^{3,5}$, \\ RAZVAN-COSMIN PETCA ${ }^{6,7}$ and MARA CARSOTE ${ }^{8,9}$
}

\begin{abstract}
${ }^{1}$ Department of Dermatology, 'Carol Davila' University of Medicine and Pharmacy, 050474 Bucharest; ${ }^{2}$ Department of Dermatology, 'Elias’ Emergency Hospital, 011461 Bucharest; ${ }^{3}$ Department of Obstetrics and Gynecology, 'Carol Davila' University of Medicine and Pharmacy, 050474 Bucharest; ${ }^{4}$ Department of Obstetrics and Gynecology,

'Elias' Emergency Hospital, 022461 Bucharest; ${ }^{5}$ Department of Obstetrics and Gynecology, University Emergency Hospital Bucharest, 050098 Bucharest; ${ }^{6}$ Department of Urology, 'Carol Davila' University of Medicine and Pharmacy, 050474 Bucharest; ${ }^{7}$ Department of Urology, 'Prof. Dr. Theodor Burghele' Clinical Hospital, 061344 Bucharest; ${ }^{8}$ Department of Endocrinology, 'Carol Davila' University of Medicine and Pharmacy, 050474 Bucharest; ${ }^{9}$ Department of Endocrinology, ‘C. I. Parhon' National Institute of Endocrinology, 011863 Bucharest, Romania
\end{abstract}

Received July 28, 2021; Accepted August 27, 2021

DOI: $10.3892 / \mathrm{etm} .2021 .10823$

\begin{abstract}
Peutz-Jeghers syndrome (PJS), a rare autosomal dominant serine/threonine kinase 11 (STK11)/ liver kinase B1 (LKBl) gene-related genodermatosis, is characterized by oral hyperpigmentation (OHP); multiple gastro-intestinal mucosal benign hamartomatous polyps causing local bleeding, occlusion, intussusception, post-resection small bowel syndrome, associated increased risk of small intestinal cancer (incidence during the third decade); and $76 \%$ cumulative higher risk than the global population of developing non-gastrointestinal tumors (female predominance) including ovarian/testicular neoplasia, pancreatic and gynecologic (breast, uterus, ovarian) cancers. Suggestive PJS-associated OHP requires STK11 genetic testing. Abdominal pain in an OHP patient may be related to PJS-associated polyps. Other features include focal
\end{abstract}

Correspondence to: Dr Mihai Cristian Dumitrascu, Department of Obstetrics and Gynecology, 'Carol Davila' University of Medicine and Pharmacy, 8 Eroilor Sanitari Street, 050474 Bucharest, Romania E-mail:drdumitrascu@yahoo.com

Abbreviations: AD, Addison disease; ACTH, adrenocorticotropic hormone; $\mathrm{AMH}$, anti-Mullerian hormone; $\mathrm{FSH}$, follicle stimulating hormone; LKB1, liver kinase B1; LCCSCT, large cell calcifying Sertoli cell tumor; LHS, Laugier-Hunziker syndrome; MMR, DNA mismatch repair; MAS, McCune-Albright syndrome; MEN, multiple endocrine neoplasia; MSH, melanocyte-stimulating hormone; OPL, oral pigmented lesions; PJS, Peutz-Jeghers syndrome; STK, serine/threonine kinase; SCTAT, sex cord tumors with annular tubules; SCT, Sertoli cell tumors; WHO, World Health Organization

Key words: Peutz-Jeghers syndrome, oral hyperpigmentation, STK11/LKB1 gene, gastrointestinal polyp, ovarian tumor, ovarian neoplasia, sex-cord stroma tumors, Sertoli cell ovarian tumors, annular tubules, testicular tumor depigmentation followed by hyperpigmentation, and xeroderma pigmentosum-like lesions. The severity of the dermatological findings is correlated with gastrointestinal polyps. The STK11 gene is linked to reserve of primordial follicles, polycystic ovary syndrome, female fertility, and spermatogenesis. PJS is associated with 2 types of ovarian sex-cord stroma tumors (SCSTs): annular tubules (SCTATs) and pure Sertoli cell tumors. SCSTs accounts for $8 \%$ of ovarian cancer and SCTATs represents $2 \%$ of SCST, which may be associated with the overproduction of progesterone. PJS-SCTAT vs. non-PJS-SCTAT reveals bilateral/multifocal, small tumors with a benign behavior vs. a unique ovarian, large tumor with increased malignant/metastasis risk. Male precocious puberty is due to large cell calcifying Sertoli cell tumors (LCCSCTs). Notably, $30-40 \%$ of LCCSCTs are caused by PJS or Carney complex. PJS-LCCSCT is not aggressive, but it may be bilateral/multifocal, with the ultrasound hallmark being micro-calcifications. Testicular, intra-tubular large cell hyalinizing Sertoli cell tumor is the second testicle neoplasia in PJS. The skin and mucosal lesions are useful markers of PJS, assisting with the early identification of hamartomatouspolyps and initiation of serial surveillance of ovarian, or testicular neoplasia.

\section{Contents}

1. Introduction

2. Aim of the review

3. Skin and mucosal manifestations

4. Differential diagnosis of oral hyperpigmentation

5. Hereditary syndromes associated with oral lesions

6. Endocrine aspects in females

7. Endocrine aspects in males

8. Gastro-intestinal polyps

9. Future considerations

10. Conclusions 


\section{Introduction}

Peutz-Jeghers syndrome (PJS), a rare genodermatosis with an autosomal dominant inheritance of a high-penetrance profile, is caused by serine/threonine kinase (STK)11 gene mutation on chromosome $19 \mathrm{p} 13.3$ (1). This is a tumor-suppressor gene, also known as liver kinase B1 ( $L K B 1)$ gene, which involves master serine-threonine protein kinase activity that communicates with different growth and angiogenesis factors representing tumorigenic pathways of associated neoplasia (2). STK11/LKB1 is also involved in signaling pathways involved in the DNA damage response to sun ultraviolet radiation as a contributor to skin cancer and it has been connected to other non-PJS-related epithelial cancers $(3,4)$. In addition, control of certain immune cells has been reported to be under the influence of the $S T K 11 / L K B 1$ gene (5).

The syndrome, with a reported incidence of $1 / 25,000$ $1 / 280,00$ persons/year, includes multiple gastro-intestinal mucosal lesions including benign hamartomatouspolyps causing local bleeding, occlusion and intussusception, post-resection small bowel syndrome; hyperpigmentation of the skin and mucosa especially at the oral and lips levels, and a higher risk of developing other non-gastrointestinal tumors including ovarian/testicular, pancreatic, breast, and uterine neoplasia (6,7) (Fig. 1). The cumulative risk of cancer is higher with $76 \%$ in the general population and with females being more exposed (8). Cancer of the small intestine usually occurs during the third decade of life making early assessment and serial follow-up crucial, once the skin lesions or gene anomalies are identified in a carrier or a specific family (9). Esophago-gastro-duodenoscopy screening and further surveillance are essential (10). Familial genetic consult is useful since the digestive disease may be asymptomatic for years (11). Lifelong follow-up is required (12).

The need for multidisciplinary teams of surveillance in PJS patients is essential, from dermatology to gastroenterology, from endocrinology to oncology, in both the pediatric and adult patients. Muco-cutaneous hyperpigmentation (deposits of melanin in skin and mucosa) represents an essential dermal clue for assessment of this multi-system condition $(13,14)$.

\section{Aim of the review}

This is a systematic, narrative review of the literature conducted based on two main aspects in PJS: on the one hand, skin and mucosa anomalies and, on the other hand, endocrine manifestations. Additional genetic and neoplasia data are provided in order to integrate the general multidisciplinary, complex image of this hereditary syndrome.

The research of the review started from the PubMed database with respect to the following key words: 'Peutz-Jeghers syndrome' and 'skin', 'mucosa', 'oral', 'endocrine, 'puberty', 'ovary', 'testes', and 'polyps'. A total of 101 references were cited between January 2010 and May 2021. Full-length original papers of different types were exclusively introduced due to the rarity of the publications in areas of interest. The selection was based on clinical relevance.

\section{Skin and mucosal manifestations}

Dermatological findings may be identified before gastrointestinal polyps and other PJS-related tumors; skin and mucosal manifestations being a valuable clue of this hereditary syndrome $(15,16)$. In some cases, vitiligo (usually focal depigmentation) may be followed by focal hyperpigmentation in the skin, oral mucosa, lips, and labia $(17,18)$. Pigmentation features may mimic xeroderma pigmentosum in the early stages (xeroderma pigmentosum is an extreme sun sensitivity-associated high risk of skin cancer) (19). Melanin hyperpigmentation present on a patient who is not previously known to have the syndrome must be biopsied in order to obtain a clear diagnostic (20). Previous findings have revealed a certain genotype-phenotype correlation of the $S T K 11 / L K B 1$ gene involving the fact that more severe dermatological findings are correlated with a more aggressive profile of gastro-intestinal hamartomatous polyps (21). A total of $90 \%$ of subjects with positive PJS criteria have STK11/LKB1 mutations; an oral hyperpigmentation suggestive for PJS is an indication of STK11 genetic testing and further familial genetic assessment (22). Abdominal pain in a patient with oral pigmentations is suggestive of a complication of a digestive PJS polyp (23). Except for a digestive field, specific protocols of investigations and follow-up regarding skin and mucosal PJS lesions remain suboptimal (24).

\section{Differential diagnosis of oral hyperpigmentation}

Skin and mucosa hyperpigmentation need to be differentiated from other conditions that are indicated by hyperpigmentation: Addison disease (AD), McCune-Albright syndrome (MAS), and Laugier-Hunziker syndrome (LHS) (25).

$\mathrm{AD}$, a chronic primary adrenal insufficiency, requiring lifelong glucocorticoid and mineralocorticoid substitution, is accompanied by hyperpigmentation at general level or at the level of scars, areolas, and skin-fold, a hyperpigmentation that is reversible to some extent under adequate endocrine therapy (26). The areas that are more exposed to the sun are also more sensitive to hyperpigmentation (26). The underlying mechanism involves high adrenocorticotropic hormone (ACTH) in addition to increased levels of melanocytestimulating hormone (MSH) (26). Concurrent focal or general depigmentation may also be found since vitiligo is associated with poly-glandular autoimmune syndrome, especially with chronic autoimmune thyroiditis (26).

MAS, an underlying endocrine condition usually accompanied by hyper-function, presents focal hyperpigmentation including 'café au lait' spots, similar to type 1 neurofibromatosis $(27,28)$.

LHS is an exceptionally rare, acquired condition (the level of evidence is case reports) associated with idiopathic hyperpigmentation at the level of the lip, acral area, oral mucosa, and even nails (29). The skin color changes are due to diffuse spreading of black macules with dimensions that vary from 1 to $5 \mathrm{~mm}(29,30)$. Longitudinal melanonychia has been described in both children and adults (30). To date, the cause is unknown (31). It seems that skin anomalies are not associated with a higher risk compared to general manifestations including endocrine conditions or non-endocrine 


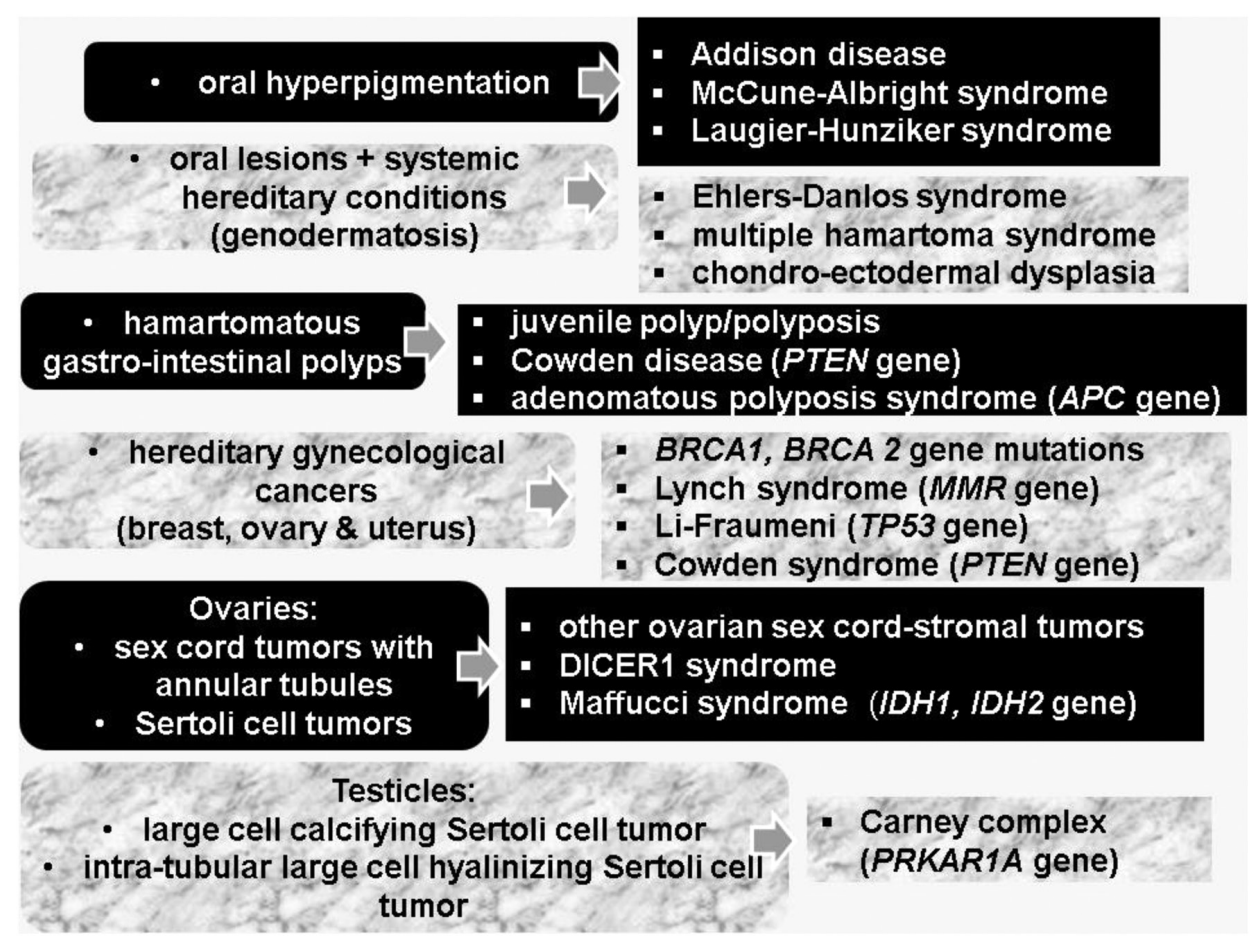

Figure 1. Differential diagnosis of the pathological elements associated with Peutz-Jeghers syndrome as discussed in the review.

tumors/cancers, as observed in PJS (32). The overall prognosis is a favorable one (33). Melanonychia striata, caused by higher melanocyte activity and secondary hyperplasia at the nail level, is also described in constitutional circumstances (individuals with dark skin), after local traumatisms or infections, in conditions such as alkaptonuria, hemochromatosis, porphyria, and LHS (34). Since LHS is a benign, rather harmless condition when it comes to general complications, the endocrine assessment is necessary to exclude the diagnosis of AD and MAS (35).

\section{Hereditary syndromes associated with oral lesions}

PJS is a type of genodermatosis representing a complex cluster of hereditary syndromes with cutaneous-mucosal manifestations in addition to systemic complications of tumor and non-tumor type (for instance, Ehlers-Danlos syndrome, multiple hamartoma syndrome, and chondro-ectodermal dysplasia) (36,37). Non-genodermatoses involve lesions such as acanthosis nigricans associated with insulin resistance, diabetes mellitus, and polycystic ovary syndrome (38). Other hereditary syndromes that involve lesions of the oral region are associated predominantly with cutaneous manifestations (Brooke-Spiegler syndrome, Muir-Torre syndrome) or predominant endocrine complications such as multiple endocrine neoplasia (MEN) type 1 (MEN gene) and type 2 (RET gene) syndrome, Carney complex (PRKARlA gene), or head and neck tumors (Cowden syndrome-PTEN gene) or systemic tumors (neurofibromatosis type 1) $(39,40)$. In many cases, the skin lesions are less important in regards to the overall prognosis even though they represent the obvious mark of the syndrome or the first step in its identification $(41,42)$. So-called familial lentiginosis dermato-endocrine syndromes include PJS, Carney complex, Cowden disease and Noonan syndrome (43). A study published in 2021 that analyzed the published papers focusing on oral pigmented lesions (OPL) introduced 9 different syndromes in individuals with a mean age at diagnosis of 35 years and female predominance $(68 \%)$ (44). Multiple lesions were more frequent than single ( $73.15 \%$ vs. $26.85 \%)$; lip followed by buccal mucosa were the more affected sites, in $75 \%$ of cases, OPL preceded the recognition of the syndrome (44).

\section{Endocrine aspects in females}

Multiple endocrine anomalies have been reported in PJS as mentioned subsequently. Individuals presenting with PJS have a lifelong higher risk of gynecological cancers with endocrine components, so-called hereditary gynecological cancers (breast, ovarian and uterine), also including those related to Lynch syndrome (mutations of the MMR gene), Li-Fraumeni (mutations of the TP53 gene), and Cowden syndrome (45). Similarity with hereditary conditions with an identical malignancy pattern includes mutations of BRCA1 and BRCA2 genes, respectively (46). Lynch syndrome is mostly related to endometrial cancer, while Cowden syndrome and Li-Fraumeni are related to breast cancer (Li-Fraumeni syndrome is also an important cause of adrenocortical carcinoma especially in the pediatric population) while PJS is equally associated with all three mentioned malignancies (47).

Conditions with benign behavior have been reported in PJS including breast hyperplasia and ovarian cysts, the STK11 gene being related to primordial follicles reserve and female fertility (48). Another potential link involves STK11 gene polymorphism in polycystic ovary syndrome that has been reported in PJS subjects, although an incidental overlap cannot be excluded (49).

PJS constitutes two types of ovarian tumors, namely sex cord tumors with annular tubules (SCTAT) and pure 
Sertoli cell tumors (SCT), both originating from ovarian sex cord-stroma $(50,51)$. Overall, ovarian sex-cord stromal neoplasia accounts for $8 \%$ of all cases diagnosed with ovarian cancer (the most frequent cause of ovarian malignancy among sex-cord stromal tumors is due to granulosa cell tumors) (52). Hereditary syndromes that have been related to this large group of ovarian sex cord-stromal tumors includes, besides PJS, DICER1 syndrome, Maffucci syndrome and Ollier disease (52). The most important hereditary syndromes in ovarian cancer are PJS, Lynch syndrome and BRCA1 and BRCA2- related disease, overall accounting for 1 out of 4-5 females with ovarian cancer (53).

SCTAT, representing $2 \%$ of all sex cord-stromal tumors, are considered very rare neoplasias (54). An increased progesterone production has been revealed in some cases (55). In non-PJS cases, one in five are malignant; thus, candidates are subjected to chemotherapy and/or surgical resection (56). Overall, the risk of malignancy is higher compared to other sex cord stromal tumors $(55,57)$. Surgical removal remains the first-line therapy, regardless of the presence of PJS (58). The presentation of SCTAT-PJS vs. SCTAT-nonPJS reveals bilateral or multifocal tumors of small size with a rather benign behavior vs. a unique ovarian tumor usually with increased diameters and a higher malignant profile, including the risk of developing distant metastases (59). Previous findings have shown synchronous detection of SCTAT and SCT in the same PJS patient (60). Other data suggest a poorer prognosis of SCTAT-PJS because of the associated higher risk of non-ovarian malignancies (61). SCTAT has also been associated with co-presence of dysgerminomas and gonadoblastomas or with Turner syndrome or endometriotic cysts, most probably incidental-based (62). The association of PJS with Sertoli-Leydig cell ovarian tumor has been reported in a very limited number of cases and it seems atypical $(63,64)$. The first recurrent Sertoli-Leydig cell tumor of the ovary was reported in 2016 in an African-American female with PJS diagnosed at the age of 3 years due to precocious puberty followed by recurrence at age of 17 years (65).

\section{Endocrine aspects in males}

Murine experiments have revealed a role of the LKB1/STK11 gene in spermatogenesis (66). Males with PJS may have low levels of follicle stimulating hormone (FSH) and high anti-Mullerian hormone (AMH), the product of testicular Sertoli cells that is inhibited by androgens under normal circumstances and escapes these mechanisms in PJS based on less understood connections (67). Gynecomastia in pre-pubertal boys and precocious puberty have been reported (68). Most cases are related to hormonally active testicular tumors, also causing precocious puberty with advanced bone age and tall stature (69). These aspects are caused by a male-specific tumor named large cell calcifying Sertoli cell tumor (LCCSCT) (70). A total of $30-40 \%$ of cases are associated with hereditary syndromes such as PJS and Carney complex while $60-70 \%$ of all LCCSCT represent sporadic forms (71).

This is an extremely rare entity derived from sperm cord cells (70). Despite the fact that the neoplasia typically does not have a very aggressive profile, one out of five men may have a bilateral/multifocal presentation (70). The presence of specific
PJS skin-mucosal lesions helps the syndromic diagnosis (70). The hallmark of LCCSCT is testicular ultrasound showing micro-calcifications (72). In addition, inhibin A assays are useful for diagnosis and during follow-up $(72,73)$. Surgical removal is the standard therapy and testes-sparing procedures or partial orchiectomy are encouraged especially in very young patients (74). Aromatase inhibitors for gynecomastia and control of advanced bone age may also be useful $(75,76)$. Since 2016, WHO (World Health Organization) has recognized another distinct PJS-related group, namely intra-tubular large-cell hyalinizing Sertoli cell tumors (77).

\section{Gastro-intestinal polyps}

The specific manifestation of PJS at the digestive system level is the presence of hamartomatous polyps, which otherwise are described as single lesion (outside PJS), juvenile polyp/polyposis or as clinical manifestation of Cowden disease $(78,79)$. Solitary Peutz-Jeghers polyp is a distinct entity and it does not underline PJS; similarly, LKB1/STK11 mutations $(80,81)$. Their evaluations combine family medical history, endoscopy findings, histological and immunohistochemistry report (after biopsy or after resection) and serial endoscopic follow-up because of post-polypectomy recurrence and increased malignancy risk $(78,82)$. The clue at first endoscopic evaluation is the number of polyps; multiple polyps generally have a genetic background and require further dermatological and endocrine workup if PJS is suspected (78). A polyp takes time to grow, thus its detection is less likely to occur during the first decade of life (83).

The most frequent sites are the small intestine as well as the colon and stomach, with the duodenum and appendix being rare sites (84). Recent findings indicate the duodenum as the most frequent location of complicated polyps (85). PJS-related polyps at the level of the small bowel need to be differentiated from other benign tumors including lipomas, leiomyomas, neurofibromas or syndromic circumstances such as adenomatous polyposis syndromes (caused by $A P C$ gene mutations) (86,87). The PJS-related polyp histological profile includes peripheral edema, mucin-filled, dilated cystic glands (88).

Not all PJS polyps have the same malignant potential of transformation because it seems that an underlying cell population is not homogenous and the exact mechanisms and prevalence of PJS polyps are not fully known at present (89). Recent findings show that hypo-methylation of the $L K B 1 / S T K 11$ promoter is correlated with a more aggressive profile (90). STK11 genotype-phenotype correlations regarding malignant potential remain a subject of discussion (91). Other authors suggest that sporadic PJS polyps are less malignant than familial cases (92). Non-STK11 gene mutations have been found in hamartomatous PJS polyps such as the $M M R$ (DNA mismatch repair) gene (93).

\section{Future considerations}

Another potential role of the STK11 gene involves a higher risk of lung cancer in PJS subjects, albeit this remains an open question (94). Scalp metastases (the general rate of malignancy spreading at this level is of 0.22 to $12 \%$ in all cancer types) from 
lung cancer have been reported in a male patient with PJS (95). KRAS-positive lung adenocarcinoma has been reported in some PJS patients (96). One third of pulmonary adenocarcinomas are related to $L K B I$ gene mutations (independently of PJS) (97). In addition, sporadic cases of non-PJS colonic cancer may be associated with STK11 gene anomalies (98). Overall, PJS is an example of the genomics approach in syndromes involving multiple cancer types and non-malignant lesions together and several medical and surgical domains are placed together in search of early clinical tools to improve the overall prognosis (99-101).

\section{Conclusions}

Specific multidisciplinary guidelines and protocols for the dermatological manifestations in addition to gastro-intestinal, endocrine and oncologic complications in PJS are sub-optimal. The skin and mucosal lesions are useful markers of the syndrome, assisting in early identification of hamartomatous polyps and serial surveillance concerning the associated higher risk of breast, uterine, ovarian, and pancreatic neoplasia.

\section{Acknowledgements}

Not applicable.

\section{Funding}

No funding was received.

\section{Availability of data and materials}

All data generated or analyzed during this study are included in this published article.

\section{Authors' contributions}

FS drafted the manuscript and critically revised the final form, AP researched the literature and generated the figure, MCD drafted the manuscript, RCP researched the literature, MC drafted the manuscript and approved the final form. All authors read and approved the final manuscript.

\section{Ethics approval and consent to participate}

Not applicable.

\section{Patient consent for publication}

Not applicable.

\section{Competing interests}

The authors declare that they have no competing interests.

\section{References}

1. Nevozinskaya Z, Korsunskaya I, Sakaniya L, Perlamutrov Y and Sobolev V: Peutz-Jeghers syndrome in dermatology. Acta Dermatovenerol Alp Pannonica Adriat 28: 135-137, 2019.
2. Zhang W, Ding Y, Zhang C, Lu Q, Liu Z, Coughlan K, Okon I and Zou MH: Deletion of endothelial cell-specific liver kinase B1 increases angiogenesis and tumor growth via vascular endothelial growth factor. Oncogene 36: 4277-4287, 2017.

3. Esteve-Puig R, Gil R, González-Sánchez E, Bech-Serra JJ, Grueso J, Hernández-Losa J, Moliné T, Canals F, Ferrer B, Cortés J, et al: A mouse model uncovers LKB1 as an UVB-induced DNA damage sensor mediating CDKN1A (p21WAF1/CIP1) degradation. PLoS Genet 10: e1004721, 2014.

4. Herrmann JL, Byekova Y, Elmets CA and Athar M: Liver kinase B1 (LKB1) in the pathogenesis of epithelial cancers. Cancer Lett 306: 1-9, 2011.

5. Zhang Y, Meng Q, Sun Q, Xu ZX, Zhou H and Wang Y: LKB1 deficiency-induced metabolic reprogramming in tumorigenesis and non-neoplastic diseases. Mol Metab 44: 101131, 2021.

6. Syarifuddin E, Masadah R, Lusikooy RE, Warsinggih, Uwuratuw JA and Faruk M: Peutz-Jeghers syndrome in a woman presenting as intussusception: A case report. Int J Surg Case Rep 79: 286-290, 2021.

7. Shrivastava A, Gupta A, Gupta A and Shrivastava J: Unusual presentation of intussusception of the small bowel with peutz jeghers syndrome: Report of a case. J Clin Diagn Res 7: 2296-2297, 2013.

8. Intratubular Armijo B, Bocklage T and Heideman R: Large cell hyalinizing sertoli cell tumor of the testes in a 4-year-old male with peutz-jeghers syndrome. J Pediatr Hematol Oncol 37: e184-e187, 2015.

9. Khanna K, Khanna V and Bhatnagar V: Peutz-Jeghers syndrome: Need for early screening. BMJ Case Rep 11: e225076, 2018.

10. Tomas C, Soyer P, Dohan A, Dray X, Boudiaf M and Hoeffel C: Update on imaging of Peutz-Jeghers syndrome. World J Gastroenterol 20: 10864-10875, 2014.

11. Ben Hammouda S, Njima M, Ben Abdeljelil N, Bellalah A, Njim L and Zakhama A: An unusual presentation revealing Peutz-Jeghers syndrome in adult. Ann Med Surg (Lond) 58: $87-90,2020$.

12. Dutta A, Ghosh SK and Kundu SK: Peutz Jegher syndrome. Indian Pediatr 52: 176-177, 2015.

13. Tacheci I, Kopacova M and Bures J: Peutz-Jeghers syndrome. Curr Opin Gastroenterol 37: 245-254, 2021.

14. Kidambi TD, Kohli DR, Samadder NJ and Singh A: Hereditary polyposis syndromes. Curr Treat Options Gastroenterol 17: 650-665, 2019.

15. Shah KR, Boland CR, Patel M, Thrash B and Menter A: Cutaneous manifestations of gastrointestinal disease: Part I. J Am Acad Dermatol 68: 211.el-e33, 2013.

16. Shen Z, Hoffman JD, Hao F and Pier E: More than just skin deep: Faciocutaneous clues to genetic syndromes with malignancies. Oncologist 17: 930-936, 2012.

17. Patel LM, Lambert PJ, Gagna CE, Maghari A and Lambert WC: Cutaneous signs of systemic disease. Clin Dermatol 29: 511-522, 2011.

18. Duan N, Zhang YH, Wang WM and Wang X: Mystery behind labial and oral melanotic macules: Clinical, dermoscopic and pathological aspects of Laugier-Hunziker syndrome. World J Clin Cases 6: 322-334, 2018.

19. Lehmann AR, McGibbon D and Stefanini M: Xeroderma pigmentosum. Orphanet J Rare Dis 6: 70, 2011.

20. Vageli DP, Doukas SG and Markou A: Mismatch DNA repair mRNA expression profiles in oral melanin pigmentation lesion and hamartomatous polyp of a child with Peutz-Jeghers syndrome. Pediatr Blood Cancer 60: E116-E117, 2013.

21. Zhang Y, Ke Y, Zheng X, Liu Q and Duan X: Correlation between genotype and phenotype in three families with Peutz-Jeghers Syndrome. Exp Ther Med 13: 507-514, 2017.

22. Duong BT and Winship I: The role of STK 11 gene testing in individuals with oral pigmentation. Australas J Dermatol 58: 135-138, 2017.

23. Chan TC and Sirlin C: Abdominal pain in a young man with oral pigmentations. J Emerg Med 50: 335-336, 2016.

24. Wagner A, Aretz S, Auranen A, Bruno MJ, Cavestro GM, Crosbie EJ, Goverde A, Jelsig AM, Latchford A, Leerdam MEV, et al: The Management of peutz-jeghers syndrome: European hereditary tumour group (EHTG) guideline. J Clin Med 10: 473, 2021.

25. Sputa-Grzegrzolka P, Wozniak Z, Akutko K, Pytrus T, Baran W, Calik J, Glatzel-Plucinska N, Domagala Z, Podhorska-Okolow M, Stawarski A and Dziegiel P: Laugier-Hunziker syndrome: A case report of the pediatric patient and review of the literature. Int J Dermatol 59: 1513-1519, 2020. 
26. Lause M, Kamboj A and Fernandez Faith E: Dermatologic manifestations of endocrine disorders. Transl Pediatr 6: 300-312, 2017.

27. Legrand MA, Raverot G, Nicolino M and Chapurlat R: GNAS mutated thyroid carcinoma in a patient with Mc Cune Albright syndrome. Bone Rep 13: 100299, 2020.

28. Sandru F, Carsote M, Valea A, Albu SE, Petca RC and Dumitrascu MC: Somatostatinoma: Beyond neurofibromatosis type 1 (Review). Exp Ther Med 20: 3383-3388, 2020.

29. Wang WM, Wang X, Duan N, Jiang HL and Huang XF. Laugier-Hunziker syndrome: A report of three cases and literature review. Int J Oral Sci 4: 226-230, 2012.

30. Lalosevic J, Zivanovic D, Skiljevic D and Medenica L: Laugier-Hunziker syndrome-Case report. An Bras Dermatol 90 (3 Suppl 1): S223-S225, 2015.

31. Wei Z, Li GY, Ruan HH, Zhang L, Wang WM and Wang X: Laugier-Hunziker syndrome: A case report. J Stomatol Oral Maxillofac Surg 119: 158-160, 2018.

32. Cusick EH, Marghoob AA and Braun RP: Laugier-Hunziker syndrome: A case of asymptomatic mucosal and acral hyperpigmentation. Dermatol Pract Concept 7: 27-30, 2017.

33. Rangwala S, Doherty CB and Katta R: Laugier-Hunziker syndrome: A case report and review of the literature. Dermatol Online J 16: 9, 2010

34. Leung AKC, Lam JM, Leong KF and Sergi CM: Melanonychia striata: Clarifying behind the Black Curtain. A review on clinical evaluation and management of the 21st century. Int J Dermatol 58: $1239-1245,2019$

35. Miličević T, Žaja I, Tešanović D and Radman M: LaugierHunziker syndrome in endocrine clinical practice. Endocrinol Diabetes Metab Case Rep: 2018: 18-0025, 2018.

36. Wilder EG, Frieder J, Sulhan S, Michel P, Cizenski JD, Wright JM and Menter MA: Spectrum of orocutaneous disease associations: Genodermatoses and inflammatory conditions. J Am Acad Dermatol 77: 809-830, 2017.

37. Babu NA, Rajesh E, Krupaa J and Gnananandar G: Genodermatoses. J Pharm Bioallied Sci 7 (Suppl 1): S203-S206, 2015.

38. Pinna R, Cocco F, Campus G, Conti G, Milia E, Sardella A and Cagetti MG: Genetic and developmental disorders of the oral mucosa: Epidemiology; molecular mechanisms; diagnostic criteria; management. Periodontol 2000 80: 12-27, 2019.

39. Kennedy RA, Thavaraj S and Diaz-Cano S: An overview of autosomal dominant tumour syndromes with prominent features in the oral and maxillofacial region. Head Neck Pathol 11: 364-376, 2017

40. Sandru F, Carsote M, Albu SE, Valea A, Petca A and Dumitrascu MC: Glucagonoma: From skin lesions to the neuroendocrine component (Review). Exp Ther Med 20: 3389-3393, 2020 .

41. Stratakis CA: Hereditary syndromes predisposing to endocrine tumors and their skin manifestations. Rev Endocr Metab Disord 17: 381-388, 2016.

42. Ponti G, Tomasi A, Manfredini M and Pellacani G: Oral mucosal stigmata in hereditary-cancer syndromes: From germline mutations to distinctive clinical phenotypes and tailored therapies. Gene 582: 23-32, 2016

43. Lodish MB and Stratakis CA: The differential diagnosis of familial lentiginosis syndromes. Fam Cancer 10: 481-490, 2011.

44. Ferreira LDS, Calderipe CB, Maass JB, Carrard VC, Martins MD, Abreu LG, Shuch LF, and Uchoa Vasconcelos AC: Oral pigmented lesions in syndromic individuals: A systematic review. Oral Dis: Jan 4, 2021 (Epub ahead of print).

45. Ueki A and Hirasawa A: Molecular features and clinical management of hereditary gynecological cancers. Int J Mol Sci 21: 9504 2020.

46. Pietragalla A, Arcieri M, Marchetti C, Scambia G and Fagotti A Ovarian cancer predisposition beyond BRCA1 and BRCA2 genes. Int J Gynecol Cancer 30: 1803-1810, 2020.

47. Chung SH, Woldenberg N, Roth AR, Masamed R, Conlon W, Cohen JG, Joines MM and Patel MK: BRCA and Beyond: Comprehensive image-rich review of hereditary breast and gynecologic cancer syndromes. Radiographics 40: 306-325, 2020

48. Jiang ZZ, Hu MW, Ma XS, Schatten H, Fan HY, Wang ZB and Sun QY: LKB1 acts as a critical gatekeeper of ovarian primordial follicle pool. Oncotarget 7: 5738-5753, 2016.

49. Smith KJ and Germain M: Polycystic ovary syndrome (PCOS) with melanocytic mucosal macules: The role of STK11 gene polymorphisms in PCOS and Peutz-Jeghers syndrome. Int J Dermatol 55: 177-180, 2016.
50. Gheorghisan-Galateanu AA, Carsote M, Terzea D, Valea A and Ghemigian A: Ovarian Sertoli cell tumours: Practical points. J Pak Med Assoc 70: 129-133, 2020.

51. Garg K, Karnezis AN and Rabban JT: Uncommon hereditary gynaecological tumour syndromes: Pathological features in tumours that may predict risk for a germline mutation. Pathology 50: 238-256, 2018.

52. Fuller PJ, Leung D and Chu S: Genetics and genomics of ovarian sex cord-stromal tumors. Clin Genet 91: 285-291, 2017.

53. Weissman SM, Weiss SM and Newlin AC: Genetic testing by cancer site: Ovary. Cancer J 18: 320-327, 2012.

54. Jaegle WT, Keyser EA, Messersmith L, Brady RO and Miller C: Extraovarian sex cord tumor with annular tubules discovered arising from a leiomyoma. Gynecol Oncol Rep 26: 17-20, 2018.

55. Young RH: Ovarian sex cord-stromal tumours and their mimics. Pathology 50: 5-15, 2018.

56. Plevová $\mathrm{P}$ and Geržová $\mathrm{H}$ : Genetic causes of rare pediatric ovarian tumors. Klin Onkol 32 (Suppl 2): S79-S91, 2019.

57. Yahaya JJ, Mshana D and Mremi A: Ovarian sex cord tumour with annular tubules in a 13-year-old female: A case report. Oxf Med Case Reports 2020: omaa024, 2020.

58. Choudhary F, Tanveer N, Mangla G and Gayatree A Non-syndromic sex cord tumor with annular tubules: A rare diagnosis. Indian J Surg Oncol 11: 313-315, 2020.

59. Han Y, Li S, Wu L, Zhang X and Cao D: Non-Peutz-Jeghers syndrome-associated ovarian sex cord tumor with annular tubules: Report of a malignant case. J Obstet Gynaecol Res 42: 224-227, 2016.

60. Ravishankar S, Mangray S, Kurkchubasche A, Yakirevich E and Young RH: Unusual sertoli cell tumor associated with sex cord tumor with annular tubules in peutz-jeghers syndrome: Report of a case and review of the literature on ovarian tumors in peutz-jeghers syndrome. Int J Surg Pathol 24: 269-273, 2016.

61. Kwon SY, Choe MS, Lee HW, Lee HJ, Shin SJ and Cho CH: Minimal deviation adenocarcinoma of the cervix and tumorlets of sex-cord stromal tumor with annular tubules of the ovary in Peutz-Jeghers syndrome. J Gynecol Oncol 24: 92-95, 2013.

62. Singh M, Mandal S and Majumdar K: Sex cord tumor with annular tubules: An incidental finding in an endometriotic cyst-the first known co-occurrence. Biomed Res Int 2014: 970243, 2014.

63. Howell L, Bader A, Mullassery D, Losty P, Auth M and Kokai G: Sertoli Leydig cell ovarian tumour and gastric polyps as presenting features of Peutz-Jeghers syndrome. Pediatr Blood Cancer 55: 206-207, 2010.

64. Poiana C, Virtej I, Carsote M, Banceanu G, Sajin M, Stanescu B, Ioachim D, Hortopan D, and Coculescu M: Virilising Sertoli-Leydig cell tumour associated with thyroid papillary carcinoma: Case report and general considerations. Gynecol Endocrinol 26: 617-622, 2010.

65. Bellfield EJ and Alemzadeh R: Recurrent ovarian Sertoli-Leydig cell tumor in a child with Peutz-Jeghers syndrome. Oxf Med Case Reports 2016: omw048, 2016.

66. Kong F, Wang M, Huang X, Yue Q, Wei X, Dou X, Peng X, Jia Y, Zheng K, Wu T, et al: Differential regulation of spermatogenic process by Lkb1 isoforms in mouse testis. Cell Death Dis 8: e3121, 2017.

67. Valeri C, Lovaisa MM, Racine C, Edelsztein NY, Riggio M, Giulianelli S, Venara M, Bedecarrás P, Ballerini MG, di Clemente N, et al: Molecular mechanisms underlying AMH elevation in hyperoestrogenic states in males. Sci Rep 10: 15062, 2020.

68. Zhang LJ, Su Z, Liu X, Wang L and Zhang Q: Peutz-Jeghers syndrome with early onset of pre-adolescent gynecomastia: A predigree case report and clinical and molecular genetic analysis. Am J Transl Res 9: 2639-2644, 2017.

69. Renes JS, Knijnenburg J, Chitoe-Ramawadhdoebe S, Gille JJP, de Bruin $\mathrm{C}$ and Barge-Schaapveld DQCM: Possible hints and pitfalls in diagnosing Peutz-Jeghers syndrome. J Pediatr Endocrinol Metab 31: 1381-1386, 2018.

70. Kaluzny A, Matuszewski M, Wojtylak S, Krajka K, Cichy W, Plawski A, Gintowt A and Lipska BS: Organ-sparing surgery of the bilateral testicular large cell calcifying Sertoli cell tumor in patient with atypical Peutz-Jeghers syndrome. Int Urol Nephrol 44: 1045-1048, 2012.

71. Tracey AJ and Cerwinka WH: Benign large-cell calcifying sertoli tumor of the testis in a 13-year-old male patient treated with partial orchiectomy: Urology 107: 226-228, 2017. 
72. Simões-Pereira J, Santos F, Lopes L and Limbert C: Prepubertal gynaecomastia in a boy with Peutz-Jeghers syndrome: Managing the aromatase overexpression. J Pediatr Endocrinol Metab 31: $1149-1154,2018$

73. Gourgari E, Saloustros E and Stratakis CA: Large-cell calcifying Sertoli cell tumors of the testes in pediatrics. Curr Opin Pediatr 24: 518-522, 2012.

74. Pelit ES, Erol B, Zenginkinet T and Çaşkurlu T: Testis-sparing surgery of unilateral testicular large-cell calcifying Sertoli cell tumor: A sporadic case. Turk J Urol 44: 370-372, 2018.

75. Koç Yekedüz M, Şıklar Z, Burgu B, Kuloğlu Z, Kocaay P, Çamtosun E, İsakoca M, Kansu A, Soygür T and Berberoğlu M: Response to anastrozole treatment in a case with peutz-jeghers syndrome and a large cell calcifying Sertoli cell tumor. Clin Res Pediatr Endocrinol 9: 168-171,2017.

76. Crocker MK, Gourgari E, Lodish M and Stratakis CA: Use of aromatase inhibitors in large cell calcifying sertoli cell tumors: Effects on gynecomastia, growth velocity, and bone age. J Clin Endocrinol Metab 99: E2673-E2680, 2014.

77. Idrees MT, Ulbright TM, Oliva E, Young RH, Montironi R, Egevad L, Berney D, Srigley JR, Epstein JI and Tickoo SK; Members of the international society of urological pathology testicular tumour panel: The World Health Organization 2016 classification of testicular non-germ cell tumours: A review and update from the International Society of Urological Pathology Testis Consultation Panel. Histopathology 70: 513-521, 2017.

78. Cauchin E, Touchefeu Y and Matysiak-Budnik T: Hamartomatous tumors in the gastrointestinal tract. Gastrointest Tumors 2: 65-74, 2015.

79. Rosty C: The Role of the surgical pathologist in the diagnosis of gastrointestinal polyposis syndromes. Adv Anat Pathol 25: 1-13, 2018.

80. Suzuki K, Higuchi H, Shimizu S, Nakano M, Serizawa H and Morinaga S: Endoscopic snare papillectomy for a solitary Peutz-Jeghers-type polyp in the duodenum with ingrowth into the common bile duct: Case report. World J Gastroenterol 21: 8215-8220, 2015.

81. Endo K, Kawamura K, Murakami K, Murakami K, Nagao M, Satoh T, Takasu A, Kogure T, Hirota M, Meguro T, et al: A case of jejunal solitary Peutz-Jeghers polyp with intussusception identified by double-balloon enteroscopy. Clin J Gastroenterol 13 : $1129-1135,2020$

82. Kumar S, Arora P and Goswami P: Recurrent intestinal obstruction in a patient of Peutz-Jeghers syndrome. J Cancer Res Ther 15: 252-254, 2019

83. Mărginean CO, Meliţ LE, Patraulea F, Iunius S and Mărginean MO: Early onset Peutz-Jeghers syndrome, the importance of appropriate diagnosis and follow-up: A case report. Medicine (Baltimore) 98: e16381, 2019.

84. Duan SX, Wang GH, Zhong J, Ou WH, Fu MX, Wang FS, $\mathrm{Ma}$ SH and Li JH: Peutz-Jeghers syndrome with intermittent upper intestinal obstruction: A case report and review of the literature. Medicine (Baltimore) 96: e6538, 2017.

85. Rodríguez Lagos FA, Sorlí Guerola JV, Romero Martínez IM and Codoñer Franch P: Register and clinical follow-up of patients with Peutz-Jeghers syndrome in Valencia. Rev Gastroenterol Mex 85: 123-139, 2020.
86. De Latour RA, Kilaru SM and Gross SA: Management of small bowel polyps: A literature review. Best Pract Res Clin Gastroenterol 31: 401-408, 2017.

87. Achatz MI, Porter CC, Brugières L, Druker H, Frebourg T, Foulkes WD, Kratz CP, Kuiper RP, Hansford JR, Hernandez HS, et al: Cancer screening recommendations and clinical management of inherited gastrointestinal cancer syndromes in childhood. Clin Cancer Res 23: e107-e114, 2017.

88. Shaco-Levy R, Jasperson KW, Martin K, Samadder NJ, Burt RW, Ying J and Bronner MP: Morphologic characterization of hamartomatous gastrointestinal polyps in Cowden syndrome, Peutz-Jeghers syndrome, and juvenile polyposis syndrome. Hum Pathol 49: 39-48, 2016.

89. Linhart H, Bormann F, Hutter B, Brors B and Lyko F: Genetic and epigenetic profiling of a solitary Peutz-Jeghers colon polyp. Cold Spring Harb Mol Case Stud 3: a001610, 2017.

90. Li T, Lin W, Zhao Y, Zhu J, Sun T and Ren L: Distinct promoter methylation patterns of LKB1 in the hamartomatous polyps of Peutz-Jeghers syndrome and its potential in gastrointestinal malignancy prediction. Orphanet J Rare Dis 15: 208, 2020

91. Wang Z, Wu B, Mosig RA, Chen Y, Ye F, Zhang Y, Gong W, Gong L, Huang F, Wang X, et al: STK11 domain XI mutations: Candidate genetic drivers leading to the development of dysplastic polyps in Peutz-Jeghers syndrome. Hum Mutat 35: 851-858, 2014

92. Jedrzkiewicz J, Quencer K, Matynia AP, Morrow E, Pletneva M and Barraza G: Peutz-jeghers type polyp of the appendix with review of literature. Case Rep Pathol 2019: 7584070, 2019.

93. Zhang Z, Duan FX, Gu GL and Yu PF: Mutation analysis of related genes in hamartoma polyp tissue of Peutz-Jeghers syndrome. World J Gastroenterol 26: 1926-1937, 2020.

94. Jung I, Gurzu S and Turdean GS: Current status of familial gastrointestinal polyposis syndromes. World J Gastrointest Oncol 7: 347-355, 2015

95. Yu Q, Subedi S, Tong Y, Wei Q, Xu H, Wang Y, Gong Y and Shi Y: Scalp metastases as first presentation of pulmonary adenocarcinomas: A case report. Onco Targets Ther 11: 6147-6151, 2018.

96. Zaba O, Holbe D, Aretz S and Grohé C: LKB1 mutant in a KRAS activated adenocarcinoma of the lung associated with Peutz-Jeghers syndrome: A case report. Lung Cancer 82: 368-369, 2013

97. Osoegawa A, Kometani T, Nosaki K, Ondo K, Hamatake M, Hirai F, Seto T, Sugio K and Ichinose Y: LKB1 mutations frequently detected in mucinous bronchioloalveolar carcinoma. Jpn J Clin Oncol 41: 1132-1137, 2011.

98. Kojima Y, Ohtsuka K, Ishii S, Aso N, Ohki A, Hashimoto Y, Takeuchi H, Ohnishi H and Abe N: STK11 p.F354L germline mutation in a case of multiple gastrointestinal tumors. Case Rep Gastroenterol 14: 547-553, 2020

99. Boda D: Cellomics as integrative omics for cancer. Curr Proteomics 10: 237-245, 2013.

100. Neagu M, Constantin C, Tanase C and Boda D: Patented biomarker panels in early detection of cancer. Recent Patents Biomarkers 1: 10-14, 2011.

101. Lupu M, Caruntu A, Caruntu C, Papagheorghe LML, Ilie MA, Voiculescu V, Boda D, Constantin C, Tanase C, Sifaki M, et al: Neuroendocrine factors: The missing link in non melanoma skin cancer. Oncol Rep 38: 1327-1340, 2017. 